\title{
EDITORIAL
}

\section{When rheumatology meets hepatology: are anti-TNFs safe in hepatitis B virus carriers?}

\author{
Tim L Jansen* \\ See related research by Charpin et al., http://arthritis-research.com/content/11/6/R179
}

\begin{abstract}
Over the past decades, more effective and less toxic biologicals have revolutionized rheumatology therapy in our battle against the autoimmune chronic inflammation of rheumatoid arthritis and spondyloarthropathy. But what about for patients who have previously had an infection of the liver? Prior hepatitis B virus infection clearly presents a challenge for clinicians. In a study by Charpin and colleagues of 21 patients whose hepatitis B virus serology suggested carrier status, anti-TNF treatment appeared to be safe during a limited follow-up period of 3 years. Studies are needed with longer follow-up, particularly in patients with low antibody titres (antiHBc). In the 3-year period, however, about $30 \%$ of the patients developed significant lowering of antibody titres, which may become relevant during long-term follow-up. Charpin and colleagues are the first to reveal promising data on the relative safety of anti-TNFs in a small series of hepatitis B carriers for up to 3 years.
\end{abstract}

In the previous issue of Arthritis Research \& Therapy Charpin and colleagues present French results from an interesting cohort of 21 hepatitis B virus (HBV) carriers with active rheumatoid arthritis or spondyloarthropathy being treated with antibodies to TNF [1]. What do we know about anti-TNF therapy in patients who have recovered from HBV infection? Hepatology has provided knowledge on HBV infection and antivirals have made hepatitis a potentially well-treatable disease since three decades ago [2]. For the past couple of decades, monoclonal antibodies against TNF have been available,

${ }^{*}$ Correspondence: t.jansen@znb.nl

Department of Rheumatology, Medical Centre Leeuwarden, POB 888, 8934 AD Leeuwarden, The Netherlands revolutionizing antirheumatic therapy [3]. Together with immunological progress, however, has come clinical complexity. For a rheumatologist encountering a patient with severe and active rheumatoid arthritis or spondyloarthropathy who is also an HBV carrier, hepatitis is regarded as a significant comorbidity. The rheumatologist is trained not to rest until the inflammatory disease has gone into remission; to achieve this target, he will prescribe all disease-modifying antirheumatic drugs (DMARDs), including anti-TNFs. Now a difficult question arises: how to safely achieve complete remission. Methotrexate, the cornerstone of our best disease modifying regimens, is contraindicated in liver disease.

HBV, a DNA virus transmitted percutaneously, sexually, and perinatally, affects up to 400 million people worldwide. HBV infection accounts for up to 5,000 deaths in the United States each year and 1 million deaths worldwide from cirrhosis, liver failure, and hepatocellular carcinoma. Important viral proteins include an envelope protein, hepatitis B surface antigen (HBsAg), a structural nucleocapsid core protein, hepatitis $B$ core antigen ( $\mathrm{HBcAg})$, and a soluble nucleocapsid protein, hepatitis B e antigen (HBeAg). Serum HBsAg is a marker of HBV infection, and antibodies against HBsAg signify recovery. Serum $\mathrm{HBeAg}$ is a marker of active viral replication and may be accompanied by serum levels of HBV DNA that are 100,000 to $1,000,000$ IU per milliliter or higher. Eradication of HBV infection is difficult as long-enduring, covalently closed circular DNA (cccDNA) becomes established in hepatocytic nuclei from where HBV DNA becomes integrated into the host genome. The study by Charpin and colleagues included 58 patients with serologically cured HBV infection - that is, HBsAgnegative plus anti-HBc-positive patients - and of these, 24 had been treated with anti-TNFs for rheumatoid arthritis or spondylitis. Additionally, three were lost due to withdrawn consent $(\mathrm{n}=1)$, HBV-unrelated death $(\mathrm{n}=1)$ and being lost from follow-up $(\mathrm{n}=1)$. Finally, 21 HBV carriers being treated with anti-TNFs were included: 3 being treated with adalimumab, 14 with etanercept, and 4 with infliximab. 
In the United States and Western Europe, most acute HBV infections occur during adolescence and early adulthood due to sexual activity, intravenous drug use, and occupational exposure. In immunocompetent adolescents and adults, a strong cellular immune response to 'foreign' HBV proteins expressed by hepatocytes results in clinically apparent acute hepatitis, which in $99 \%$ of infected people affects clearance of the infection $[4,5]$. The progression of liver disease after HBV infection is fostered by active virus replication, indicated by a serum HBV DNA level of 1,000 to 10,000 IU per milliliter. In such cases anti-TNFs are contraindicated but antiviral regimens should be considered. A serum HBV DNA level $<1,000$ IU per milliliter and normal alanine aminotransferase (ALT) levels are considered to be indicators of inactive carriers with only a low risk of clinical progression [6]; rarely, reactivation can occur spontaneously or with immunosuppression [7-9]. As clinical and histological improvement accompanies reductions in HBV replication, interventions reducing HBV replication are indicated in such cases to limit progressive liver disease. When virus infection has been overcome, immunosuppression is relatively contraindicated. Practically, outcomes of $\mathrm{HBV}$ infection evolve only over decades. Clinical trials, as well as Charpin and colleagues' study, are limited to only several years, rarely up to 5 years. Surrogate, achievable endpoints are therefore used, including serologic (HBsAg recurrence, representing recurrent hepatitis versus adequate antiHBc levels, suggesting carrier state), virologic ( $\log _{10}$ reduction versus increase in the HBV DNA level, or suppression versus expression of HBV DNA to an (un)detectable level $(<10$ to $100 \mathrm{IU}$ per millilitre)), as well as a commonly used biochemical parameter (normalization versus increase above the upper normal limit of the serum ALT level).

Over the past decades, more effective and less toxic biologicals have revolutionized rheumatology therapy in our battle against the chronic autoimmune inflammation of rheumatoid arthritis and spondyloarthropathy. Unmet needs are adequate access and long-term safety issues regarding tumor and infection risk. What if one has previously had an infection of the liver? Patients who have had a prior $\mathrm{HBV}$ infection clearly present a challenge for clinicians. If $\mathrm{HBV}$ serology suggests a carrier state, then anti-TNF appears to be safe during a limited follow-up period of 3 years. Studies are needed with longer follow-up, particularly in patients with low antibody titres (anti-HBc). In a 3-year period, however, about $30 \%$ of the French patients in the study by Charpin and colleagues developed significant lowering of antibody titres, which may become relevant during long-term follow-up. Charpin and colleagues are the first to reveal promising data on the relative safety of anti-TNFs in a small series of HBV carriers over a period of 3 years.

\section{Abbreviations}

$\mathrm{ALT}=$ alanine aminotransferase; $\mathrm{HBCAg}=$ hepatitis $\mathrm{B}$ core antigen; $\mathrm{HBeAg}=$ hepatitis B e antigen; $\mathrm{HBsAg}=$ hepatitis $B$ surface antigen; $H B V=$ hepatitis $B$ virus; TNF = tumour necrosis factor.

\section{Competing interests}

The author declares that he has no competing interests.

Published: 21 January 2010

\section{References}

1. Charpin C, Guis S, Colson P, Borentain P, Mattéi JP, Alcaraz P, Balandraud N, Thomachot B, Roudier J, Gérolami R: Safety of TNF-blocking agents in rheumatic patients with serology suggesting past hepatitis $B$ state: results from a cohort of 21 patients. Arthritis Res Ther 2009, 11:R179.

2. Greenberg HB, Pollard RB, Lutwick LI, Gregory PB, Robinson WS, Merigan TC: Effect of leukocyte interferon on hepatitis B virus infection in patients with chronic active hepatitis. N Engl J Med 1976, 295:517-522.

3. Scott DL, Kingsley GH: Tumor necrosis factor inhibitors for rheumatoid arthritis. N Engl J Med 2006, 355:704-712.

4. Hoofnagle JH, Doo E, Liang TJ, Fleischer R, Lok AS: Management of hepatitis B: summary of a clinical research workshop. Hepatology 2007, 45:1056-1075.

5. Dienstag JL, Isselbacher KJ: Acute viral hepatitis. In Harrison's Principles of Internal Medicine. Volume 2. 16th edn. Edited by Kasper DL, Braunwald E, Fauci AS, Hauser SL, Longo DL, Jameson JL. New York: McGraw-Hill; 2005:1822-1838

6. Manno M, Cammà C, Schepis F, Bassi F, Gelmini R, Giannini F, Miselli F, Grottola A, Ferretti I, Vecchi C, De Palma M, Villa E: Natural history of chronic HBV carriers in northern Italy: morbidity and mortality after 30 years. Gastroenterology 2004, 127:756-763.

7. Hoofnagle JH, Dusheiko GM, Schafer DF, Jones EA, Micetich KC, Young RC, Costa J: Reactivation of chronic hepatitis $B$ virus infection by cancer chemotherapy. Ann Intern Med 1982, 96:447-449.

8. Lok AS, Liang RH, Chiu EK, Wong KL, Chan TK, Todd D: Reactivation of hepatitis $B$ virus replication in patients receiving cytotoxic therapy: report of a prospective study. Gastroenterology 1991, 100:182-188.

9. Raftery G. Chronic viral hepatitis and TNF blockade. Rheumatology (Oxford) 2007, 46:1381.

doi:10.1186/ar2899

Cite this article as: Jansen $T L$ : When rheumatology meets hepatology: are anti-TNFs safe in hepatitis B virus carriers? Arthritis Research \& Therapy 2010, 12:103. 